\title{
Status Report on the Fabrication of Fuel Cladding Chemical Interaction Test Articles for ATR Irradiations
}

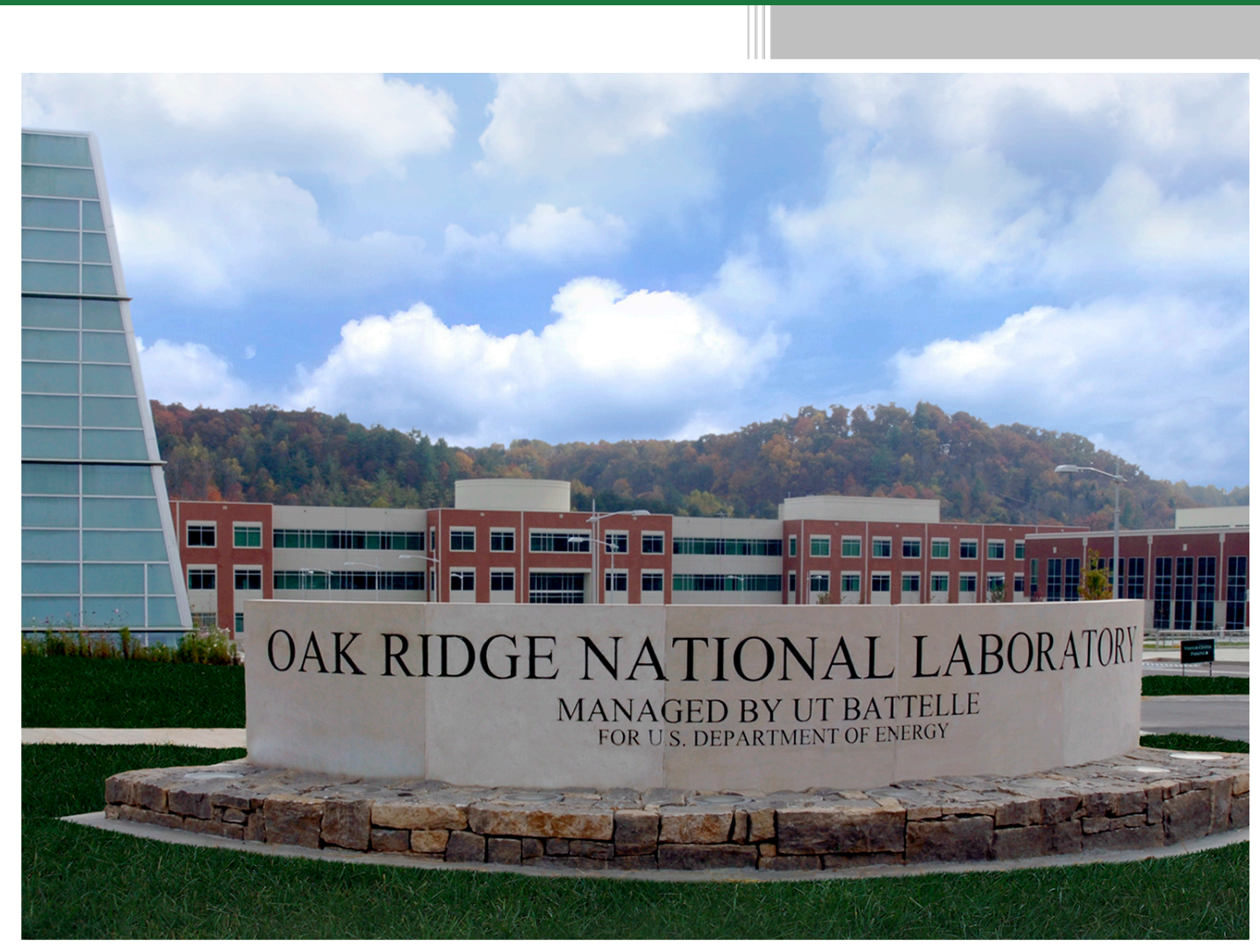

Approved for public release. Distribution is unlimited.
Kevin G. Field

Richard H. Howard

September 28, 2015 


\section{DOCUMENT AVAILABILITY}

Reports produced after January 1, 1996, are generally available free via US Department of Energy (DOE) SciTech Connect.

Website http://www.osti.gov/scitech/

Reports produced before January 1, 1996, may be purchased by members of the public from the following source:

National Technical Information Service

5285 Port Royal Road

Springfield, VA 22161

Telephone 703-605-6000 (1-800-553-6847)

TDD 703-487-4639

Fax 703-605-6900

E-mail info@ntis.gov

Website http://www.ntis.gov/help/ordermethods.aspx

Reports are available to DOE employees, DOE contractors, Energy Technology Data Exchange representatives, and International Nuclear Information System representatives from the following source:

Office of Scientific and Technical Information

PO Box 62

Oak Ridge, TN 37831

Telephone 865-576-8401

Fax 865-576-5728

E-mail reports@osti.gov

Website http://www.osti.gov/contact.html

This report was prepared as an account of work sponsored by an agency of the United States Government. Neither the United States Government nor any agency thereof, nor any of their employees, makes any warranty, express or implied, or assumes any legal liability or responsibility for the accuracy, completeness, or usefulness of any information, apparatus, product, or process disclosed, or represents that its use would not infringe privately owned rights. Reference herein to any specific commercial product, process, or service by trade name, trademark, manufacturer, or otherwise, does not necessarily constitute or imply its endorsement, recommendation, or favoring by the United States Government or any agency thereof. The views and opinions of authors expressed herein do not necessarily state or reflect those of the United States Government or any agency thereof. 
Fuel Cycle Research and Development (FCRD)

\section{Status Report on the Fabrication of Fuel Cladding Chemical Interaction Test Articles for ATR Irradiations}

Kevin G. Field and Richard Howard

Date Published: September $28^{\text {th }}, 2015$

Prepared by

OAK RIDGE NATIONAL LABORATORY

Oak Ridge, Tennessee 37831-6283

managed by

UT-BATTELLE, LLC

for the

US DEPARTMENT OF ENERGY

under contract DE-AC05-00OR22725 



\section{CONTENTS}

Page

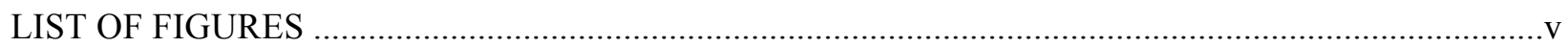

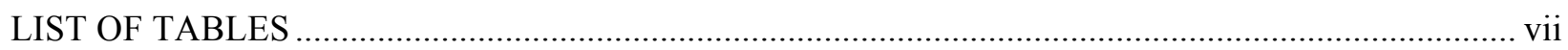

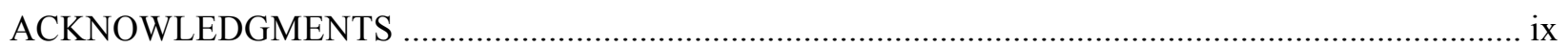

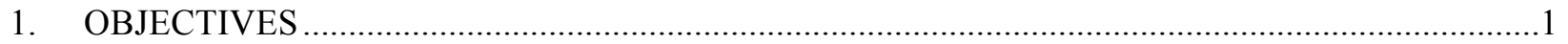

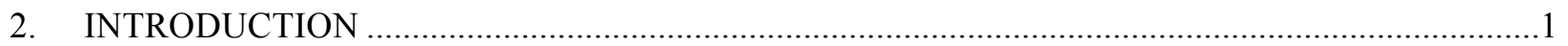

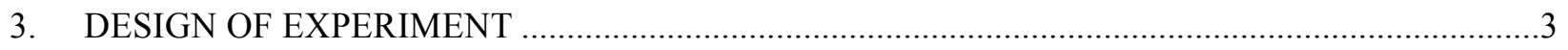

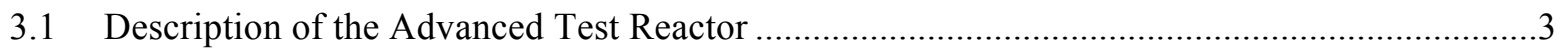

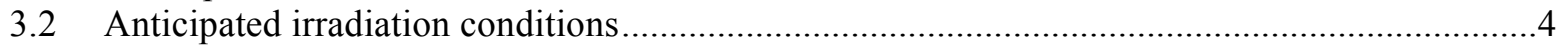

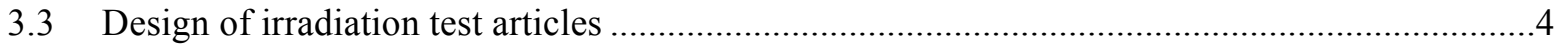

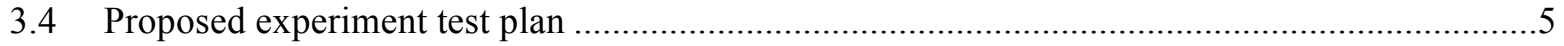

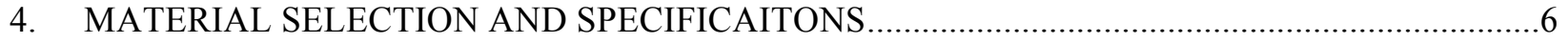

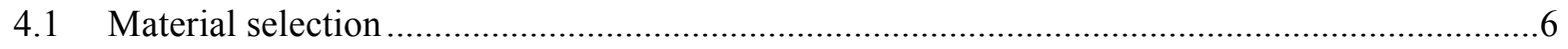

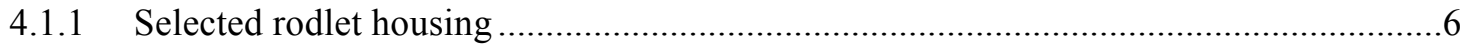

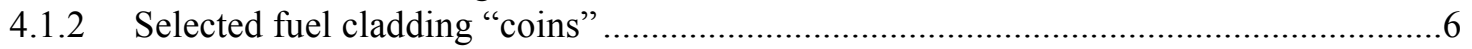

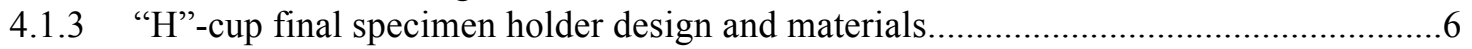

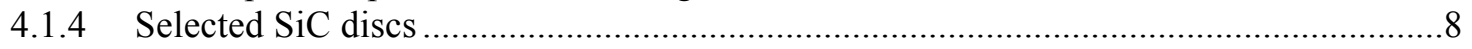

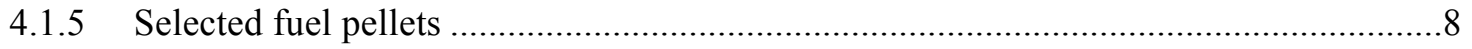

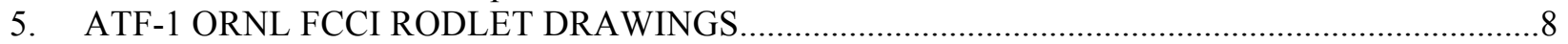

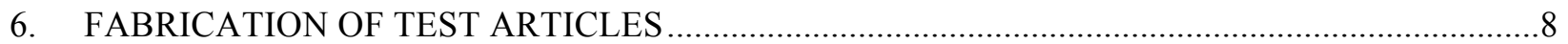

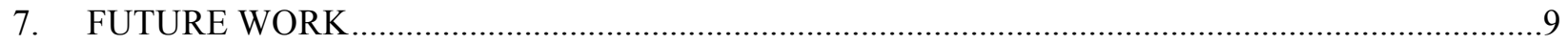

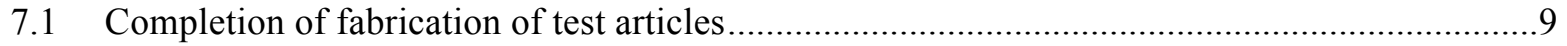

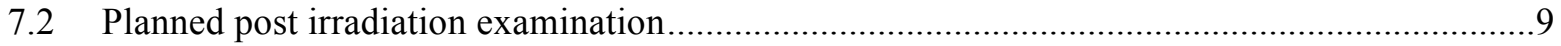

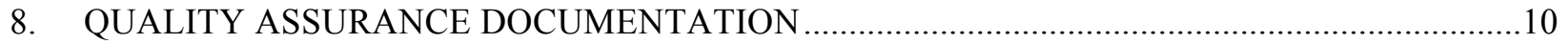

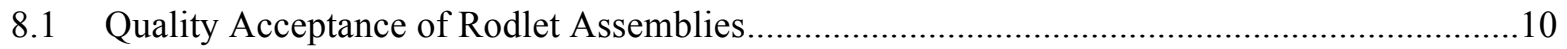

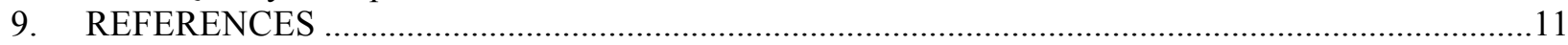

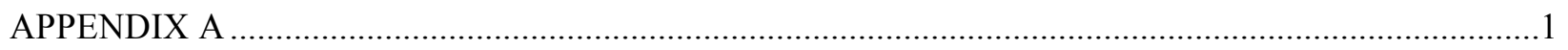

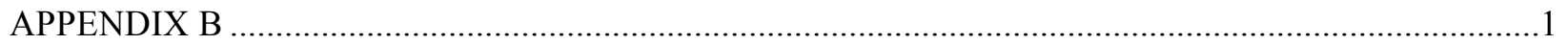





\section{LIST OF FIGURES}

Figure $\quad$ Page

Figure 1: Cross-section of ATR core highlighting locations of the 4 small-I positions (reproduced

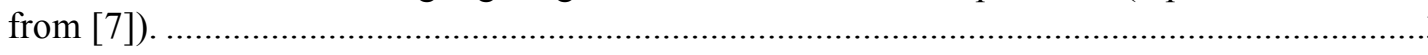

Figure 2: Schematic of ATF-1 ORNL FCCI rodlet. Red assemblies are the "H"-cup sub-assemblies, green assemblies are the cladding "coins", black assemblies are the $\mathrm{UO}_{2}$ fuel discs, blue assemblies are part of the " $\mathrm{H}$ "-cup assembly to constrain axial swelling of the fuel, gray assemblies are the rodlet housing, and the gold assembly is the outer capsule which is in contact with ATR primary coolant.

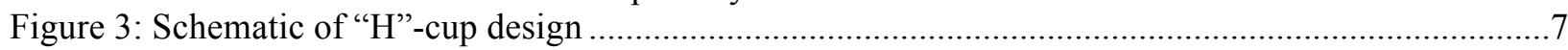

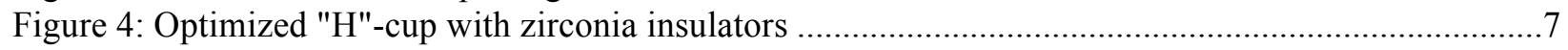





\section{LIST OF TABLES}

\section{Table}

Page

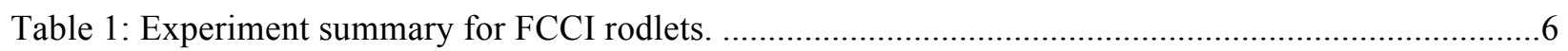

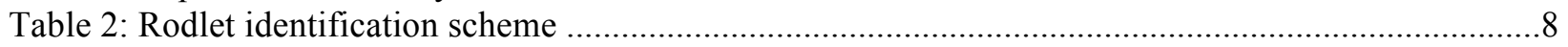





\section{ACKNOWLEDGMENTS}

This research was sponsored by the U.S. Department of Energy, Office of Nuclear Energy, Advanced Fuel Campaign of the Fuel Cycle R\&D program. This report was authored by UT-Battelle, LLC under Contract No. DE-AC05-00OR22725 with the U.S. Department of Energy. 


\section{OBJECTIVES}

The objective for the fabrication of the fuel-cladding chemical interaction (FCCI) test articles for the Advanced Test Reactor (ATR) is to provide test specimens that simulate the interactions between prototype cladding materials and commercially standard $\mathrm{UO}_{2}$ fuel. The design of the test article allows for the simultaneous irradiation of diffusion-couple-like sub-assemblies allowing for multiple cladding materials to be tested within a single experiment. This configuration greatly decreases the lead-time to get critical data on the FCCI between candidate cladding materials and prototypical $\mathrm{UO}_{2}$ fuel. Data generated from this experiment will help with providing a robust application for a Licensing Amendment Request (LAR) to use candidate-cladding material in combination with $\mathrm{UO}_{2}$ fuel in a Lead Test Rod (LTR) insertion into a commercial light water reactor (LWR). To accomplish these objectives and meet the project goals, a collaboration between Oak Ridge National Laboratory (ORNL) and Idaho National Laboratory (INL) has been established.

\section{INTRODUCTION}

$\mathrm{FeCrAl}$ alloys are a promising new class of alloys for light water reactor (LWR) applications due to their superior oxidation and corrosion resistance in high temperature environments. Additionally, they exhibit other behaviors conducive to nuclear reactor core internal applications including having the same excellent radiation-induced cavity swelling resistance as other ferritic alloy systems [1], a high resistance to environmental stress corrosion cracking (SCC) [2], and they maintain good mechanical properties at and above normal operating conditions of LWRs [3]. The culmination of these properties has enticed the research and development (R\&D) community to strongly consider using FeCrAl alloys as a new cladding option with enhanced accident tolerance over the industry standard Zr-based cladding options. In particular, the high temperature steam oxidation resistance is the main attractive feature for using FeCrAl alloys as an accident tolerant cladding option in LWR applications.

The current R\&D efforts have focused on the alloy composition and processing routes to generate nuclear grade $\mathrm{FeCrAl}$ alloys with optimized properties for enhanced accident tolerance while maintaining properties needed for normal operation conditions. Therefore, the composition and processing routes must be optimized to maintain the high temperature steam oxidation (typically achieved by increasing the $\mathrm{Cr}$ and Al content) while still exhibiting properties conducive to normal operation in a LWR (such as radiation tolerance where reducing $\mathrm{Cr}$ content is favorable). Within this balancing act is the addition of understanding the influence on composition and processing routes on the $\mathrm{FeCrAl}$ alloys for fuel-cladding chemical interactions (FCCI).

FCCI could be detrimental to the performance of the candidate FeCrAl cladding in two ways. The first is chemical attack of the cladding could lead to reduction in the cladding thickness and lead to eventual weakening of the cladding wall. If such an effect occurs, the cladding thickness would need to be increased prior to irradiation. However, a thicker cladding, required to mitigate issues with FCCI, would increase the neutronic penalty, which is the second potential impact of using FeCrAl cladding. Increased neutronic penalty could lead to changes in the cycle length or a need for increased enrichment of the fuel.

Previous studies on stainless steel claddings for fast reactor fuel pin applications have indicated that FCCI can occur in two ways: 1) the first is a uniform oxidation of the matrix which results in a decrease in the cladding thickness in a uniform way, 2) the other is the intergranular penetration of oxygen and fission productions along the grain boundaries in the cladding. The uniform attack can be on the order of tens of microns but the intergranular attack has been found to be non-uniform and could penetrate the entire thickness of the cladding [4]. Such intergranular attack could also embrittle grain boundaries leading to 
severe embrittlement of the cladding under irradiation. Clearly, FCCI is a major performance issue for any candidate cladding material.

Currently, limited knowledge exists on FCCI for the FeCrAl-UO $\mathrm{U}_{2}$ clad-fuel system. A series of experiments were conducted under the Atomic Energy Commission (AEC) Fuels and Materials Development Program [5]. This R\&D program ran through the 1960s and evaluated a range of alloys and fuel concepts, typically for fast-breeder reactor applications. During the course of the program, efforts were made to understand the physical-chemical effects of several candidate FeCrAl cladding concepts with $\mathrm{UO}_{2}$-based cermet fuel. Unfortunately, this effort was terminated in FY-66, and hence an extensive database was never fully developed. The work completed did indicate some key findings important towards understanding FCCI for today's modern FeCrAl- $\mathrm{UO}_{2}$ clad-fuel system. The first is that $\mathrm{Al}$ additions in the $\mathrm{FeCrAl}$ claddings would reduce $\mathrm{UO}_{2}$ above temperatures of $1000^{\circ} \mathrm{C}$. Once the $\mathrm{UO}_{2}$ was reduced, the free $U$ was mobile enough to diffuse rapidly through the cladding leading to transport of $U$ from the inner cladding to the outer surface of the cladding. This effect, $U$ transport through the cladding, was eliminated once the oxygen reacted with the $\mathrm{Al}$ to form $\mathrm{Al}_{2} \mathrm{O}_{3}$, which was found to be stable and limited further diffusion of $\mathrm{Al}$ into $\mathrm{UO}_{2}$. The formation of $\mathrm{Al}_{2} \mathrm{O}_{3}$ prevented further reduction of $\mathrm{UO}_{2}$ and production of free $\mathrm{U}$. This effect, according to annual reports of the AEC program, did not appear at temperatures below $1000^{\circ} \mathrm{C}$. It was also stated that above $4 \mathrm{wt} . \% \mathrm{Al}$, no significant change was observed in their FeCrAl-UO ${ }_{2}$ interaction tests.

Although the AEC program provides some insights on the FCCI for the FeCrAl-UO $\mathrm{U}_{2}$ fuel-clad system, it does not fully allow for evaluation of the susceptibility of FeCrAl during prototypical normal operation in an LWR. Of primary interest is the influence of fission products and the radiation environment, where factors such as radiation-induced segregation can change localized chemistry at the grain boundary, enhancing or retarding FCCI. The AEC program conducted tests within a simple autoclave where the fuel would not be generating fission products and radiation-induced phenomena would not occur. Furthermore, these tests were conducted at elevated temperatures $\left(500-1200^{\circ} \mathrm{C}\right)$. Therefore, no information regarding FCCI exists at lower temperatures that could be relevant to LWR conditions. The synergistic effects of radiation and temperature on the FCCI of $\mathrm{FeCrAl}-\mathrm{UO}_{2}$ continue to be a significant knowledge gap.

To overcome the knowledge gaps on the FCCI for the FeCrAl- $\mathrm{UO}_{2}$ clad-fuel system a series of fueled irradiation tests have been developed for irradiation in the Advanced Test Reactor (ATR) housed at the Idaho National Laboratory (INL). The first series of tests, deemed the Accident Tolerant Fuel experiment \#1 Oak Ridge National Laboratory Loss of Coolant Accident (ATF-1 ORNL LOCA) has already been reported in FY-14 [6]. To summarize, this test used miniaturized 17x17 PWR fuel geometry rodlets of second generation FeCrAl alloys (designation C35MN [3]) fueled with industrial Westinghouse $\mathrm{UO}_{2}$ fuel. These rodlets were encapsulated within a stainless steel housing. The encapsulating steel container acted as a safety barrier between the experimental rodlets and ATR's primary coolant flow. The lack of coolantclad contact means any interactions between these two mediums, such as corrosion, cannot be evaluated using the current test series. This also means limited FCCI will be developed as cladding creep down will not occur at typical magnitudes as there is no coolant in contact with the candidate clad(s) and outward creep of the clad tube could occur due to pressurization of the rodlet due to fission gas release. Hence, the ATF-1 ORNL LOCA rodlets experiment is not an idealized experimental test bed to determine the extent, if any, of FCCI in FeCrAl- $\mathrm{UO}_{2}$ clad-fuel systems under irradiation.

To provide high fidelity experiments and more robust testing, a new series of rodlets have been developed deemed the Accident Tolerant Fuel Experiment \#1 Oak Ridge National Laboratory FCCI test (ATF-1 ORNL FCCI). The main driving factor, which is discussed in detail in following sections, was to provide a radiation environment where prototypical fuel-clad interface temperatures are met while still maintaining constant contact between industrial fuel and the candidate cladding alloys hence promoting 
FCCI between the fuel-clad systems. The other factor was to develop a test bed where multiple candidate alloys could be evaluated within a single irradiation test train, thereby reducing overall costs and increasing efficiency in alloy screening efforts. A collaboration between ORNL and INL was developed to facilitate the completion of the test bed for FCCI testing. The following report highlights the activities related to the development of the ATF-1 ORNL FCCI rodlets for irradiation in INL's ATR as part of the on-going ATF-1 experiments.

\section{DESIGN OF EXPERIMENT}

\subsection{Description of the Advanced Test Reactor}

The ATR is housed at the INL. The ATR is a pressurized, light-water moderated and cooled nuclear reactor with a beryllium reflector and a maximum power output of $250 \mathrm{MWt}$. Presently, the ATR operates with a steady power of approximately $120 \mathrm{MWt}$. The stainless steel reactor vessel is a $3.65 \mathrm{~m}$ diameter cylinder and stands $10.67 \mathrm{~m}$ high. The core is designed with 40 fuel assemblies derived from U-Al plates with highly enriched uranium arranged in a serpentine configuration. This configuration allows for the use of rotating $\mathrm{Hf}$ control cylinders providing a symmetrical axial neutron flux with 77 irradiation positions; each position is $1.2 \mathrm{~m}$ long and ranges from 1.3 to $13 \mathrm{~cm}$ in diameter. A schematic of the core can be found in Figure 1. A standard operating cycle is six to eight weeks with outages around 1 to 2 weeks with an average of 250 effective full power days (EFPD) per year. The current configuration of the ATR provides several different experiment configurations for materials and fuel testing including simple static capsules, instrumented lead experiments, pressurized water loops, and a hydraulic shuttle irradiation system. This configuration enables a large range of experiments to be conceived and executed to assist with the development of novel materials applications for nuclear energy.

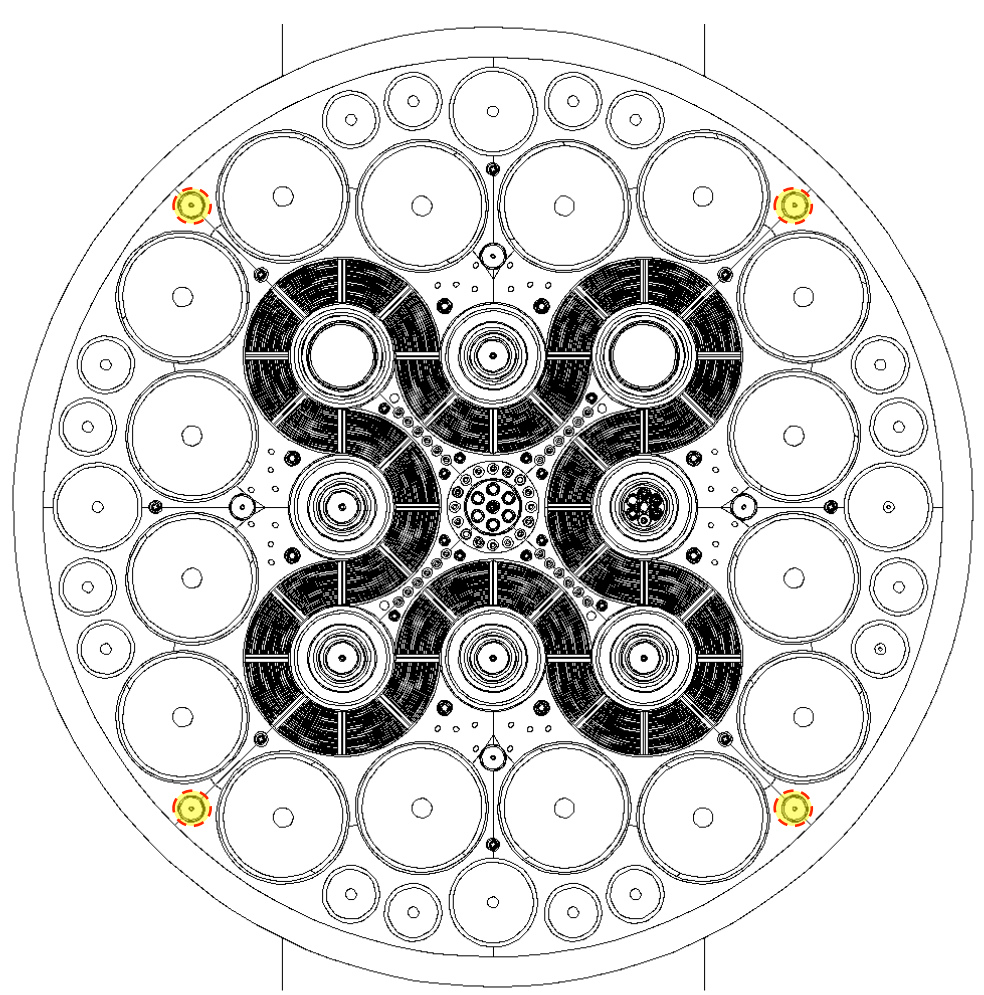

Figure 1: Cross-section of ATR core highlighting locations of the 4 small-I positions (reproduced from [7]). 


\subsection{Anticipated irradiation conditions}

The assembly design is a drop-in (non-instrumented) capsule design. The assembly is based on the mixed oxide (MOX) fuel irradiation design previously used for the DOE Fissile Materials Disposition Program (FMDP) [8]. This design incorporates three primary components: 1) the basket assembly, 2) the capsule assembly, and 3) the rodlet test assembly. As discussed, the ATF-1 configuration, modified from the MOX design, results in the candidate cladding materials used for the rodlets not being in contact with the ATR water coolant during irradiation due to the encapsulating steel capsule. The lack of coolant-clad contact eliminates any interactions between these two mediums and as such no evaluations on corrosion or other phenomena that involve primary coolant flow can be made. This also means cladding-creep down will not occur and therefore a standard fuel-pin type assembly will not have pellet-clad contact under irradiation until very high burn-up. Similar effects were observed in the MOX irradiation experiment where no strong contact FCCI was developed below $50 \mathrm{GWd}$ /MT [9]. Hence, a standard fuel-pin configuration is not an idealized geometry for FCCI testing within the constraints of the ATF-1 configuration. As described in later sections, the internals of the rodlet assembly were modified to provide a more robust test bed for FCCI screening tests.

The three-part assembly of the ATF-1 configuration was developed based on insertion into a small-I position within the ATR. The small-I positions are highlighted in Figure 1. The previous MOX design utilized the small-I positions allowing for prototypical commercial PWR operating conditions including a linear heat generation rate of $160-230 \mathrm{~W} / \mathrm{cm}$ and a clad temperature of $\sim 350{ }^{\circ} \mathrm{C}$ [7]. Four small-I positions exist within the ATR with nominal flux levels of $8.4 \times 10^{13} \mathrm{n} / \mathrm{cm}^{2}-\mathrm{s}$ (thermal) and $3.2 \times 10^{12} \mathrm{n} / \mathrm{cm}^{2}-\mathrm{s}$ (fast). This ratio of fast to thermal flux results in conditions that are not ideal for accumulating high doses (displacements per atom or dpa) within the clad. The majority of the cladding fast fluence $(\mathrm{E}>1.0 \mathrm{MeV})$ is generated due to fuel loading in the rodlet.

\subsection{Design of irradiation test articles}

The simple design of the ATF-1 ORNL LOCA experiment allowed for a rapid deployment of test rodlets for the ATF-1 series. These rodlets will provide useful information on cladding failure, such as breach, and the resistance of the clad to failure during LOCA conditions. However, as mentioned previously, the neutron spectrum in the small-I position limits the total accumulated dose in the cladding materials and therefore limits materials testing for long-term radiation tolerance. Furthermore, positions near the core centerline appear to be out of specification to obtain PWR-like rodlet conditions using the standard test configuration. Finally, the required gap between a commercial fuel pellet and the clad and the limited clad creep down capabilities of the design limit the possibility of FCCI at low burn-up values. For these reasons, the ATF-1 ORNL FCCI-rodlet design was developed.

A schematic of the proposed design is shown in Figure 2. The premise of this design is to maintain constant contact between a sintered $\mathrm{UO}_{2}$ disc (or other fuel forms) and candidate fuel clad material under irradiation. The fuel discs will be mated on top and bottom to candidate cladding "coins" or round button samples to form a diffusion-couple-like experiment.

Each fuel-clad couple will be mated within a sub-assembly (described in more detail in Section 4.1.3). The sub-assembly is designed to provide heat transfer and to constrain the $\mathrm{UO}_{2}$ fuel disc from swelling radially. To constrain the radial swelling of the fuel element, the sub-assembly resembles an " $\mathrm{H}$ " with the "wings" of the "H" cradling a single fuel element sandwiched between two cladding coins. This constraint will cause swelling primarily along the long axis of the rodlet resulting in a constant contact at the fuel-clad interface. This complete sub-assembly will be repeated vertically within the rodlet to provide assessment of several different fuel-clad combinations within a single experimental configuration. At intermittent points, passive $\mathrm{SiC}$ thermometry discs with a nominal height of $1 \mathrm{~mm}$ will be inserted into 
the stack-up to verify that experimental temperatures match the simulated temperatures obtained from design calculations. Verification of irradiation temperature is paramount, as FCCI has been shown to be temperature dependent [4].

The stacked design allows for overall reduction in the fuel inventory of each rodlet. The current configuration of the FCCI rodlet design uses 11 fuel discs of reduced height compared to the feedstock pellets leading to significant reduction in fuel volume compared to the ORNL-LOCA rodlet design. It is predicted the overall reduction in fuel inventory will allow for this rodlet design to be utilized in high power positions at the reactor midplane while maintaining reasonable temperature values. Furthermore, the axial profile of the linear heat generation rate can be utilized to achieve pellets with varying degrees of burn-up for the same exposure time. The " $\mathrm{H}$ "-cup configuration also allows for several different candidate materials to be tested within one rodlet, including wrought and oxide dispersion strengthened (ODS) FeCrAl alloys.

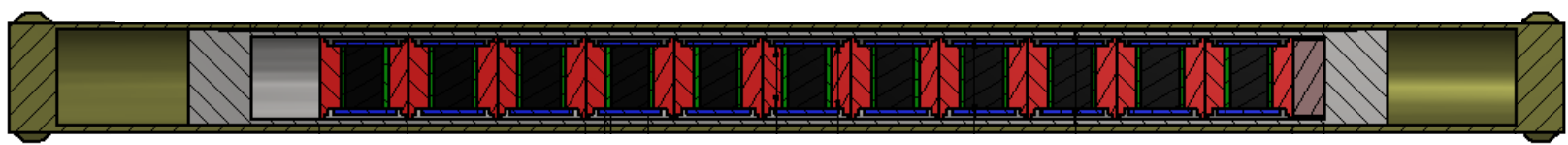

Figure 2: Schematic of ATF-1 ORNL FCCI rodlet. Red assemblies are the "H"-cup sub-assemblies, green assemblies are the cladding "coins", black assemblies are the $\mathrm{UO}_{2}$ fuel discs, blue assemblies are part of the " $H$ "-cup assembly to constrain axial swelling of the fuel, gray assemblies are the rodlet housing, and the gold assembly is the outer capsule which is in contact with ATR primary coolant.

The ORNL-proposed FCCI design has several complications in regard to deployment into the ATF-1 irradiation experiment. The primary issue is the overall complexity of the design. The "H-cup" design requires detailed 3D modeling of the rodlet to understand the temperature gradients both radially and axially. The change in design will also require a detailed analysis to verify the design does not exceed the experiment safety assurance package (ESAP). Neither of the tasks is simple, and adds a layer of extra complexity to the ATF-1 irradiation experiment.

\subsection{Proposed experiment test plan}

The primary design constraint for the FCCI rodlets is controlling the interface temperature between a clad specimen and fuel. The target temperature at the center of the fuel-specimen interface is desired to be $350^{\circ} \mathrm{C}$. Due to the axial variation in the linear heat generation rate, there will be some axial variation in the temperatures at the fuel-specimen interfaces. The fuel-specimen interface temperature should remain in the range of 275 to $425^{\circ} \mathrm{C}$ for all fuel-clad interfaces. There is also a desire to contain the radial temperature gradient across the fuel-clad interface to $\sim 20^{\circ} \mathrm{C}$ per $\mathrm{mm}$ from the center node of the interface to the outer node of the interface (i.e. reduce radial heat losses). These temperature gradients are typical of those during LWR normal operations. These temperature gradients are also small enough to assume that the temperature is relatively constant within the field-of-view for a typical optical and/or electron microscope during post-irradiation examination (PIE). Three burn-up values are to be evaluated to determine the levels of FCCI near beginning-of-life (10 GWd/MT), middle-of-life (30 GWd/MT), and end-of-life $(50 \mathrm{GWd} / \mathrm{MT})$ for a typical FeCrAl- $\mathrm{UO}_{2}$ clad-fuel system. The proposed experiment test plan was provided in INL PLN-4950, and is reproduced here in Table 1 for the test article information including the fuel type, cladding material, and targeted burn up. Based on prior experience and the ATR's typical EFPDs per year, the expected test cycle for the ATF-1 ORNL FCCI-rodlet experiment will span 70 months until completion. 
Table 1: Experiment summary for FCCI rodlets.

\begin{tabular}{|c|c|c|c|c|c|}
\hline \multirow[b]{2}{*}{ Fuel } & \multirow[b]{2}{*}{$\begin{array}{c}\text { Fuel } \\
\text { Enrichment }\end{array}$} & \multirow[b]{2}{*}{ Cladding } & \multicolumn{2}{|c|}{ Desired Irradiation Conditions } & \multirow{2}{*}{$\begin{array}{c}\text { Initial } \\
\text { \# of } \\
\text { Rodlets }\end{array}$} \\
\hline & & & $\begin{array}{l}\text { Nominal target } \\
\text { temperature at } \\
\text { interface }\left({ }^{\circ} \mathrm{C}\right) \\
\end{array}$ & $\begin{array}{c}\text { Burn-up } \\
(\mathrm{GWd} / \mathrm{MT})\end{array}$ & \\
\hline $\begin{array}{c}\text { Commercial } \\
\mathrm{UO}_{2}\end{array}$ & $4.95 \%$ & FeCrAl candidates & 350 & 10 & 1 \\
\hline $\begin{array}{c}\text { Commercial } \\
\mathrm{UO}_{2}\end{array}$ & $4.95 \%$ & FeCrAl candidates & 350 & 30 & 1 \\
\hline $\begin{array}{c}\text { Commercial } \\
\mathrm{UO}_{2}\end{array}$ & $4.95 \%$ & FeCrAl candidates & 350 & 50 & 1 \\
\hline
\end{tabular}

\section{MATERIAL SELECTION AND SPECIFICAITONS}

\subsection{Material selection}

\subsubsection{Selected rodlet housing}

The rodlet housing will be composed of commercially available 304 stainless steel (304SS). 304SS was selected as the material of choice because obtaining commercial extrusions and using familiar fabrication processes can meet the tight dimensional tolerances of the design. Furthermore, 304SS has weld procedures qualified through the American Society of Mechanical Engineers (ASME) Boiler and Pressure Vessel Code (BPVC), Section IX, and in place at ORNL (see Appendix A).

\subsubsection{Selected fuel cladding "coins"}

Fuel cladding materials will be prototype $\mathrm{FeCrAl}$ cladding materials selected from the current inventory of Generation I, Generation II, and/or ODS FeCrAl alloys out of the ORNL FeCrAl alloy development efforts. For more information on the designation tied to a Generation I or Generation II alloy, the reader is referred to the Technology Implementation Plan ATF FeCrAl Cladding for LWR Application, ORNL/TM2014/353 [10]. Alloys will be selected to probe composition (both $\mathrm{Cr}$ and $\mathrm{Al}$ effects) as well as preoxidation processes to form a protective $\mathrm{Al}_{2} \mathrm{O}_{3}$ layer. Such pre-oxidation will provide insight on whether such a processing step could be used for mitigation of FCCI between $\mathrm{FeCrAl}$ and $\mathrm{UO}_{2}$.

\subsection{3 "H"-cup final specimen holder design and materials}

An "H" - cup design was chosen to contain the fuel and specimen coins because it provides various useful features for assembly, design performance, and post irradiation examination (PIE). As the name suggests, the cross-section of the holder forms the shape of an " $H$ ", with the plenum space between the upper and lower vertical legs containing the fuel and specimens. Figure 3 provides a schematic of the "H"-cup loading configuration. This geometry is meant to promote heat transfer vertically through the fuel and specimens and then direct the energy radially out through the horizontal section of the " $\mathrm{H}$ ". In order to promote this directional heat transfer, the " $\mathrm{H}$ "-cup material shown in Figure 3 was separated into two separate components with different materials (see Figure 4). The horizontal component was selected to be fabricated from molybdenum, given its excellent thermal conductivity and stability in a radiation field. 
However, selecting the material for the vertical component was not so straightforward. The good thermal conductivity of Mo counteracted the desired heat transfer paths, which exacerbated the radial temperature gradients in the fuel and specimens. Stabilized zirconia $\left(\mathrm{Y}_{2} \mathrm{O}_{3}+\mathrm{ZrO}_{2}\right.$, etc.) was selected for the vertical component material due to its desirable thermal expansion, heat generation rate, and low thermal conductivity. The vertical 'insulator ring' greatly improved the holder assembly's heat transfer while not having a huge impact on the overall design (see Figure 4).

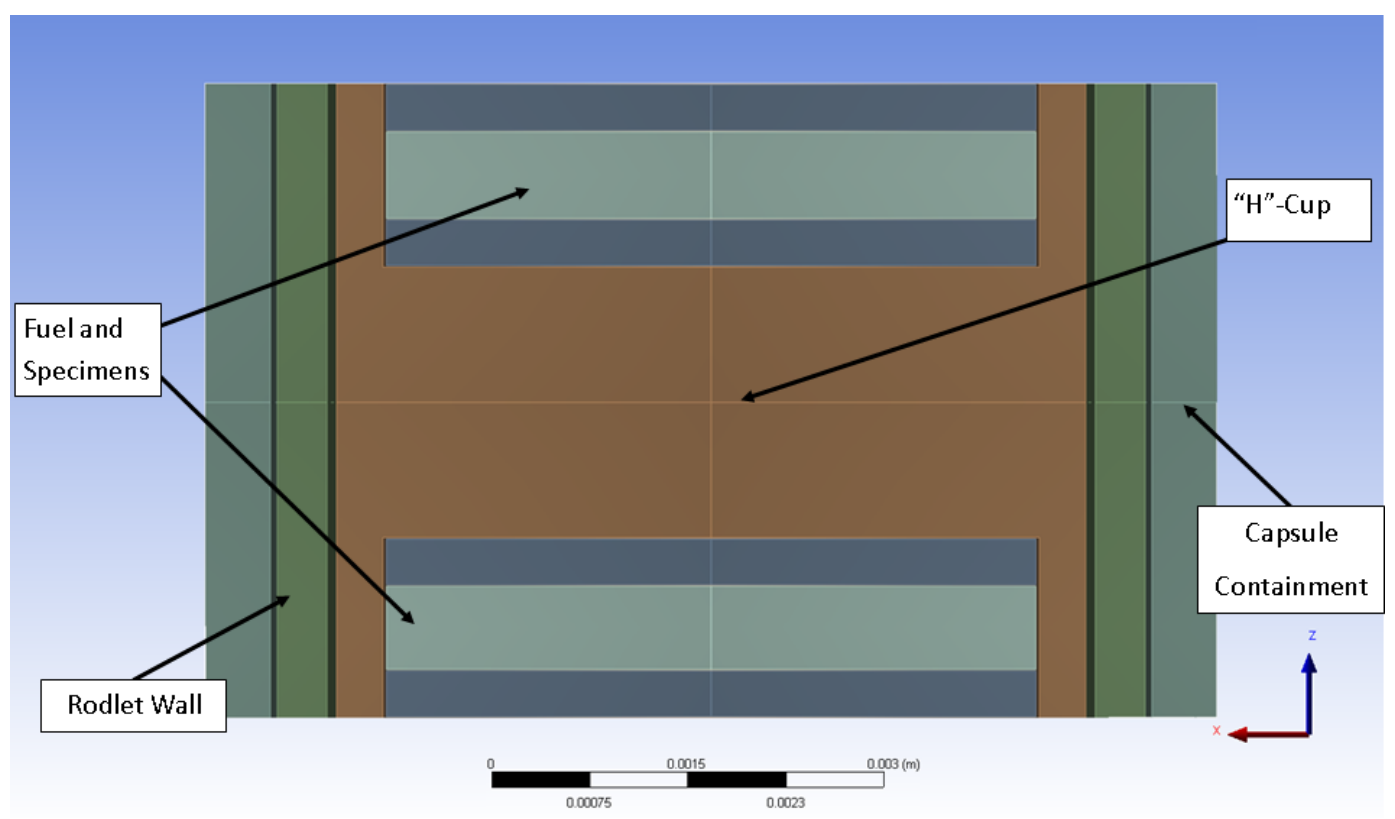

Figure 3: Schematic of "H"-cup design

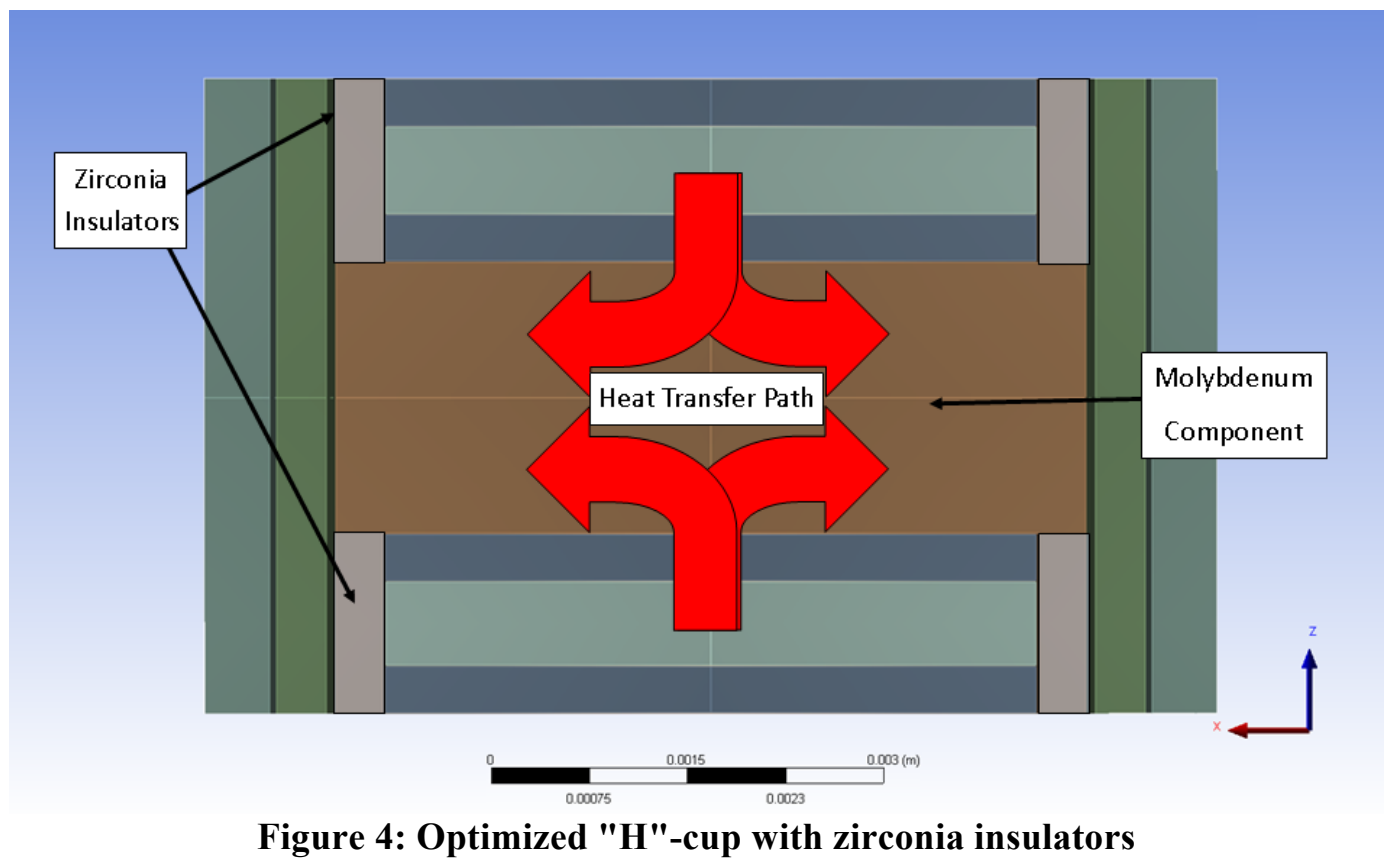




\subsubsection{Selected SiC discs}

High purity CVD-SiC (>99.999\%) from Dow Chemical Co. will be used as the base material for SiC components. The same CVD processed $\mathrm{SiC}$ has seen widespread use in other irradiations within ATR and other materials test reactors.

\subsubsection{Selected fuel pellets}

The fuel to be used for the ATF-1 ORNL FCCI test is industrial fuel provided by Westinghouse. The $\mathrm{UO}_{2}$ fuel pellets that will serve as feed stock for disc sample fabrication meet the impurity limits stated in ASTM C776-06 and have a O/U ratio of $2.0-0.01 /+0.02$ and a nominal ${ }^{235} \mathrm{U}$ enrichment of $4.95 \mathrm{wt}$. \%. These pellets are required to meet the specifications detailed in Fabrication Control Plan for ORNL ATF Test Specimens to be Irradiated in the ATR, INL-PLN-4950. Due to a non-disclosure agreement, the details on the characterization for the $\mathrm{UO}_{2}$ data cannot be provided within this report.

These fuel pellets have been supplied to INL and are currently being manufactured to make the required fuel discs. Fuel slices are being prepared using either a low or high-speed precision section saw to the rough thickness requirements of the design. The outer diameter of the fuel slices will be reached using wet centerless grinding. Each fuel disc will be assigned a unique specimen identifier.

Following fuel disc fabrication, the fuel discs will be dimensionally inspected to determine the final thickness and diameter. These values will be recorded for each disc along with the mass in the final quality assurance documentation.

\section{ATF-1 ORNL FCCI RODLET DRAWINGS}

Based on the experimental design outlined in Sections 3 and 4, a preliminary drawing of the design has been developed. This drawing, INL drawing 605047, details the dimensional requirements and inspection points of the rodlet housing and internal sub-assemblies. A draft of the drawing can be found in Appendix $\mathrm{B}$ as finalized drawings have not been released. Each rodlet will be marked with a unique identifier, as described in Table 2.

Table 2: Rodlet identification scheme

\begin{tabular}{|l|c|c|c|c|c|}
\hline Rodlet ID & $\begin{array}{c}\text { ID on } \\
\text { Bottom } \\
\text { Endplug }\end{array}$ & $\begin{array}{c}\text { ID on Top } \\
\text { Endplug }\end{array}$ & $\begin{array}{c}\text { Fuel } \\
\text { Designation }\end{array}$ & $\begin{array}{c}\text { Bond } \\
\text { Material }\end{array}$ & $\begin{array}{c}\text { Weld } \\
\text { Gas }\end{array}$ \\
\hline FCA-C1 & None & $\begin{array}{c}\mathrm{O} \\
\mathrm{C} 1\end{array}$ & FR-series & $\mathrm{He}$ & $\mathrm{He}$ \\
\hline FCA-C2 & None & $\begin{array}{c}\mathrm{O} \\
\mathrm{C} 2\end{array}$ & FR-series & $\mathrm{He}$ & $\mathrm{He}$ \\
\hline FCA-C3 & None & $\begin{array}{c}\mathrm{O} \\
\mathrm{C} 3\end{array}$ & FR-series & $\mathrm{He}$ & $\mathrm{He}$ \\
\hline
\end{tabular}

\section{FABRICATION OF TEST ARTICLES}

Fabrication of test articles will commence upon release of finalized drawings by INL and the successful completion of the design gate review. Currently, the final design review between all interested parties is tentatively scheduled for November $18^{\text {th }}, 2015$. This design review and final approval has been delayed 
due to the complexity of the design. The governing document for the fabrication of the ATF-1 ORNL FCCI rodlets is the Fabrication Control Plan for ORNL ATF Test Specimens to be Irradiated in the ATR, INL-PLN-4950. This document describes the controlling factors and requirements for the completion of a compliant fabrication of the test articles.

\section{FUTURE WORK}

\subsection{Completion of fabrication of test articles}

The test article design was completed as part of fulfilling the objectives within this work effort. The future work associated with this task includes:

- Release finalized INL drawing 605047 - INL lead

- Complete design review and technical checks of structural and thermal calculations - INL lead

- Quoting and fabrication of rodlet (test article) parts - ORNL lead

- Receipt inspection of all non-radiological components - ORNL lead

- Receipt of fuel and INL supplied parts at ORNL - ORNL lead

- Perform test article assembly and welding - ORNL lead

- Complete final testing and examination of capsules - ORNL lead

- Perform ORNL quality assurance review of test article fabrication package - ORNL lead

- Ship successful test articles to INL - ORNL lead

The formal INL design review mentioned previously is required for moving forward with the action items listed above.

\subsection{Planned post irradiation examination}

Discharged rodlets from the reactor will be cooled in the ATR canal for a minimum of 30 days. After cooling, the capsule assemblies will be shipped to the Hot Fuels Examination Facility (HFEF) at INL. Preliminary PIE can be conducted within the HFEF. HFEF capabilities include the following:

- Visual examination/inspection

- Neutron radiography

- Cladding profilometry

- Gamma-ray spectroscopy

- Fission gas collection and analysis

- Burn-up determination

- Metallography

The primary interest for PIE activities of the ATF-1 ORNL FCCI rodlets is the deconsolidation of the subassemblies while maintaining the integrity of the fuel-clad interface within each sub assembly. The fuel-clad components will be cross-sectioned axially to provide cross-sections of the interface and enable the determination of FCCI, if any. Follow on activities will include the determination of the reaction products, the extent of penetration, and distribution of fission products within each candidate cladding. $\mathrm{SiC}$ carbide discs will be cleaned and then used to determine the nominal irradiation temperature of each capsule. 


\section{QUALITY ASSURANCE DOCUMENTATION}

\subsection{Quality Acceptance of Rodlet Assemblies}

To facilitate quality acceptance of rodlet assemblies at INL, copies of material test reports, dimensional inspections, weld inspections and other fabrication documentation shall be sent to INL for review prior to shipment to INL. A comprehensive list of these requirements is as follows:

1. Fuel Materials (These documents are on file at ORNL and INL)

a. Copies of reports for isotopic analysis of the fuel.

b. Copies of reports for chemical analysis of the major constituents of the fuel.

c. Copies of reports showing the levels of impurity elements as specified by the experimenter.

2. Rodlet Materials

a. Chemical analysis reports/certifications from a qualified supplier for rodlet tube stock.

b. Chemical analysis reports/certifications from a qualified supplier for end cap stock(s).

c. Cleaning reports for all components and final assemblies

3. Rodlet Weld Qualification Data (See Appendix A)

a. Weld qualification reports detailing all welds, repairs, modifications and testing shall be included in the data package.

b. Weld qualification data sheets for the welder(s) performing the welds.

4. Rodlet Summary Data

a. Rodlet loading record listing specifying component (fuel, insulators, springs) identifiers and loading order.

b. Welding and fill gas details. These should include gas purity, oxygen levels (in ppm) and internal pressure at a minimum. Atmospheric pressure at the time of loading should also be included if glove box gauge pressure is used to determine internal pressure.

c. Helium leak test report of the sealed rodlet (performed at ORNL prior to shipping and at INL after receipt and prior to loading in the capsule). The rodlets must have a leak rate of $<1 \times 10^{-7} \mathrm{cc}(\mathrm{He}) / \mathrm{s}$ in order to be acceptable.

d. Visual inspection report of the rodlet welds:

i. Acceptance requirements will be included in the ORNL visual inspection reports and the ORNL He leak test reports.

e. Radiographs of rodlet loading and condition of internal components (performed at ORNL prior to shipping and at INL after receipt and prior to loading in the capsule).

f. OPTIONAL radiography (for information only) at INL after receipt and prior to loading in the capsule per the discretion of the responsible engineer.

g. Dimensional certification reports documenting geometric dimensional inspections called for in drawings 604498 and 604499 will be provided.

$\mathrm{h}$. Special handling and capsule loading instructions, as applicable.

5. Rodlet Drawings (See Appendix B)

a. The As Built Data Package shall include current fuel rodlet design drawings. All supporting documentation for the rodlet assembly will reference these current drawings.

6. Rodlet Certification

a. Each rodlet shall be accepted by the Responsible Engineer and a Quality Engineer indicating that the rodlet data package is complete and acceptable for capsule assembly.

7. Non Conforming Rodlets

a. All fuel materials, components, and finished fuel test specimens (rodlets) that do not meet the drawing specifications and any additional specifications shall have either a deviation or nonconformance report justifying acceptance. 
The QA package for the FCCI rodlet is currently in preparation and the complete package will be distributed upon fabrication of the finalized rodlet.

\section{REFERENCES}

[1] K.G. Field, X. Hu, K.C. Littrell, Y. Yamamoto, L.L. Snead, Radiation tolerance of neutron-irradiated model Fe-Cr-Al alloys, Journal of Nuclear Materials, 465 (2015) 746-755.

[2] R.B. Rebak, Alloy Selection for Accident Tolerant Fuel Cladding in Commercial Light Water Reactors, Metallurgical and Materials Transactions E, (2015).

[3] Y. Yamamoto, B.A. Pint, K.A. Terrani, K.G. Field, L.L. Snead, Development and property evaluation of nuclear grade wrought $\mathrm{FeCrAl}$ fuel cladding for light water reactors, Accepted in - Journal of Nuclear Materials, (2015).

[4] D.C. Fee, C.E. Johnson, Fuel-cladding chemical interaction in uranium-plutonium oxide fast reactor fuel pins, Journal of Nuclear Materials, 96 (1981) 80-104.

[5] H.S. Edwards, K.M. Bohlander, Physico-chemical studies of Fe-Cr-Al-clad fuel systems, in: AEC Fuels and Materials Development Program, General Electric, 1968.

[6] K.G. Field, R.H. Howard, M. Teague, Fabrication control plan for ORNL ATF test specimens to be irradiated in the ATR, in, Idaho National Laboratory, Idaho Falls, ID, 2014.

[7] S. Hayes, K. Barrett, Irradiation Testing of Accident Tolerant Fuels in the ATR (The ATF-1 Test Series), in, Idaho National Laboratory, Idaho Falls, ID, 2013.

[8] L.J. Ott, R.N. Morris, Irradiation tests of mixed-oxide fuel prepared with weapons-derived plutonium, Journal of Nuclear Materials, 371 (2007) 314-328.

[9] L. Ott, Personal communication on MOX fuels irradiation test plan, in, 2013.

[10] M. Snead, L.L. Snead, K.A. Terrani, K.G. Field, A. Worrall, K.R. Robb, Y. Yamamoto, J. Powers, S. Dryepondt, B.A. Pint, X. HU, Technology Implementation Plan ATF FeCrAl Cladding for LWR Application, in, Oak Ridge National Laboratory, Oak Ridge, TN, 2014. 


\section{APPENDIX A}

\begin{tabular}{|c|c|c|c|}
\hline \multicolumn{3}{|c|}{$\begin{array}{l}\text { WELD } 350 \text { - PIPE WELDING PROCEDURE SPECIFICATION (WPS) } \\
\text { ASME VII \& B31.3 }\end{array}$} & NUMBER: GT88-1(PP) \\
\hline DATE: & \multicolumn{3}{|l|}{ May 7,2015} \\
\hline COMPANY NAME: & \multicolumn{3}{|l|}{ UT-Battelle, LLC } \\
\hline WELDING PROCESS: & \multicolumn{3}{|c|}{ GTAW Manual \& Semiautomatic } \\
\hline BASE MATERIAL(S): & \multicolumn{3}{|c|}{ 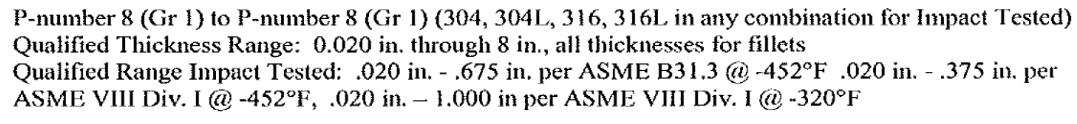 } \\
\hline IMPACTS: & \multicolumn{3}{|c|}{ Yes, qualified to $-452^{\circ} \mathrm{F} \mathrm{min}$. temperature } \\
\hline FILLER MATERIAL(S): & \multicolumn{3}{|c|}{$\begin{array}{l}\text { Type: SFA } 5.9 \text { F-number } 6 \text { and A-number } 8 \\
\text { Class: Not Impact Tested - See Table 1 (ER3XX) } \\
\text { Impact Tested - ER308L or ER3 16LLF }<5 \text { FN only } \\
\text { Deposited Thickness Range for Not Impact Tested: Through } 8 \text { in., fillet unlimited } \\
\text { Deposited Thickness Range for Impact Tested: @ }-452^{\circ} \mathrm{F} \\
\text { Through .675 ASME B31.3 - Fillet Unlimited } @-452^{\circ} \mathrm{F} \\
\text { Through } .375 \text { ASME VIII Div. I - Fillet Unlimited @ }-452^{\circ} \mathrm{F} \\
\text { Through } 1.00 \text { ASME VIII Div. I - Fillet unlimited @ }-320^{\circ} \mathrm{F}\end{array}$} \\
\hline PREHEAT/INTERPASS: & \multicolumn{3}{|l|}{$\begin{array}{l}\text { Preheat: } 50^{\circ} \mathrm{F} \min . \\
\text { Interpass: } 350^{\circ} \mathrm{F} \max .\end{array}$} \\
\hline $\begin{array}{l}\text { WELD SERVICE } \\
\text { CONDITIONS }\end{array}$ & Operating range $>20^{\circ} \mathrm{F}$ & \multicolumn{2}{|c|}{ Operating range $<20^{\circ} \mathrm{F}$ through $-452^{\circ} \mathrm{F}$} \\
\hline WELDING & NOT IMPACT & IMPACT TESTED & IMPACT TESTED \\
\hline \multicolumn{4}{|l|}{ Manual: } \\
\hline *Process & GTAW & GTAW & GTAW \\
\hline Increment & All & All & All \\
\hline *Polarity & DCSP - No pulsing & DCSP - No pulsing & DCSP - No pulsing \\
\hline *Electrode & AWS A-5.12 & AWS A-5.12 & AWS A -5.12 \\
\hline Electrode diam. (in.) & $1 / 16,3 / 32,1 / 8$ & $1 / 16,3 / 32,1 / 8$ & $1 / 16,3 / 32,1 / 8$ \\
\hline$*$ Weld filler material & See Table 1 & $\begin{array}{l}\text { ER308L or ER316L } \\
\text { Low Ferrite }\end{array}$ & ER316L, Low Ferrite \\
\hline Filler mt'l diam. (in.) & $\begin{array}{l}0.030,0.035,0.045 \\
1 / 16,3 / 32,1 / 8\end{array}$ & $\begin{array}{l}0.030,0.035,0.045 \\
1 / 16,3 / 32,1 / 8\end{array}$ & $\begin{array}{l}0.030,0.035,0.045 \\
1 / 16,3 / 32,1 / 8\end{array}$ \\
\hline${ }^{*}$ Current (amps) & $15-165$ & $60-108 *$ & $85-280 * *$ \\
\hline Arc voltage (volts) & $7-14$ & $10-14 *$ & $13-25 * *$ \\
\hline *Joules & N/A & $29 \mathrm{KJ} / \mathrm{in} . / \mathrm{max}$ & $140 \mathrm{KJ} / \mathrm{in} / \mathrm{max}$ \\
\hline *Travel & N/A & 2.6 ipm min.** & $3-10 * *$ \\
\hline *Shielding gas & Argon & Argon & Argon \\
\hline *Shielding gas (cfli) & $15-35$ & $15-35$ & $15-35$ \\
\hline *Purging gas & Argon or Helium ${ }^{1,2}$ & Argon or Helium ${ }^{1.2}$ & Argon or Helium ${ }^{1.2}$ \\
\hline *Purging gas (cfh) & 5 min & $5 \mathrm{~min}$ & 5 min \\
\hline \multicolumn{4}{|c|}{$\begin{array}{l}\text { **See Impact Tested Joint Welding Procedure on Page } 3,316 \mathrm{LLF} \text { wire to }-452^{\circ} \mathrm{F} \text {. } \\
\text { ***See Impact Tested Joint Welding Procedure on Page } 3,316 \mathrm{LLF} \text { wire to }-320^{\circ} \mathrm{F} \text {. }\end{array}$} \\
\hline \multicolumn{4}{|c|}{ Page 1 of 3} \\
\hline
\end{tabular}




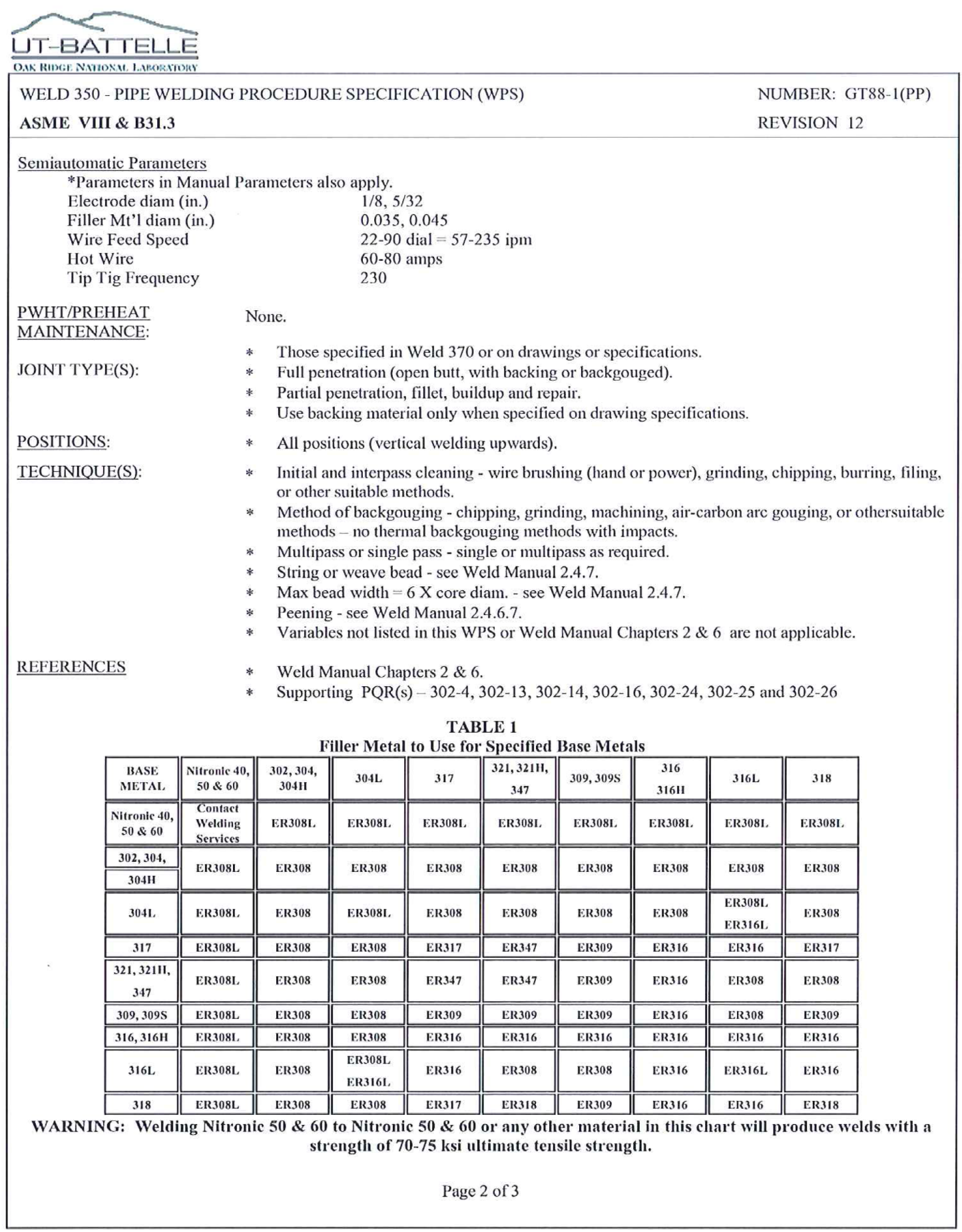




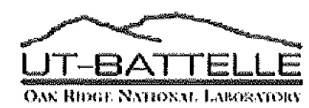

WELD 350 - PIPE WELDING PROCEDURE SPECIFICATION (WPS)

NUMBER: GT88-1(PP)

ASME VII \& B31.3

REVISION 12

For $3 \times X H$ base materials, use ER $3 X X H$ filler or filler with greater than $0.04 \%$ carbon.

Unless otherwise specified, ER308L may be substituted for ER308, ER309L for ER309, and ER316L for ER316.

Note: Other deviations from this chart are permitted when required by drawing specifications if the change complies with the $\mathrm{F}$ and A numbers of this procedure, and are approved by the Welding Program Manager.

**IMPACT TESTED JOINT WELDING PROCEDURE FOR 308L WIRE TO $-452^{\circ} \mathrm{F}$

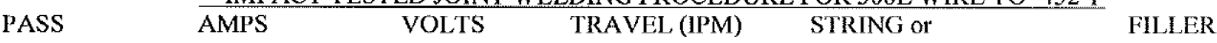
MIN. WEAVE

$\begin{array}{lccccc}1 & 65-75 & 11 & 3.6 & \text { STRING } & 3 / 32 \mathrm{in} . \\ 2 & 95-108 & 14 & 3.2 & \text { WEAVE } & 3 / 32 \mathrm{in} . \\ 3+ & 85-100 & 13-14 & 2.9 & \text { WEAVE } & 3 / 32 \mathrm{in} .\end{array}$

* *IMPACT TESTED JOINT WELDING PROCEDURE FOR 316LLF WIRE TO $-452^{\circ} \mathrm{F}$

$\begin{array}{llll}\text { AMPS VOLTS TRAVEL (IPM) STRING or } & \text { FILLER }\end{array}$

\begin{tabular}{|c|c|c|c|c|c|}
\hline 1 & $60-75$ & $10-11$ & 3.25 & STRING & $3 / 32 \mathrm{in}$ \\
\hline 2 & $82-98$ & $13-14$ & 2.6 & WEAVE & $3 / 32 \mathrm{in}$. \\
\hline
\end{tabular}

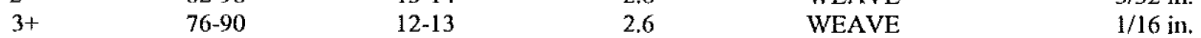

***IMPACT TESTED IOINT WELDING PROCEDURE FOR 316LLF WIRE TO-320\%

$\begin{array}{llll}\text { AMPS } & \text { VOLTS TRAVEL (IPM) } & \text { STRING OR } & \text { FILLER }\end{array}$

$\begin{array}{cccccc}1 & 60-80 & 10-13 & 3-5 & \text { STRING } & 3 / 32 \mathrm{in}, \\ 2 & 70-100 & 10-13 & 3-7 & \text { STRING OR } & 3 / 32 \mathrm{in.} \\ 3+ & & & & \text { WEAVE } & \\ 3 / 32 \mathrm{in.}\end{array}$

NOTE:

1. Helium may be used as a backing or purge gas under certain circumstances (i.e. Maintenance welding on helium systems, an upflow purge, or confined space welding)

2. Solar Flux type B may be used when conditions warrant use. Multipass welds require application before each pass. Mix with Methyl Alcohol to form thin paste, apply with brush coating 1/4" each side of weld root minimum. Allow to dry before welding. Reapply for each additional pass until $3 / 16$ " thickness is achieved.

Approved By: 80 Mollg S. D. Mobley, ORNL Welding Program Manager UT-Battelle, LLC; Oak Ridge National Laboratory
Reviewed By:

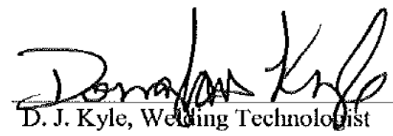

Date: May 7.2015

Date: $\quad$ May 7,2015 


\section{APPENDIX B}

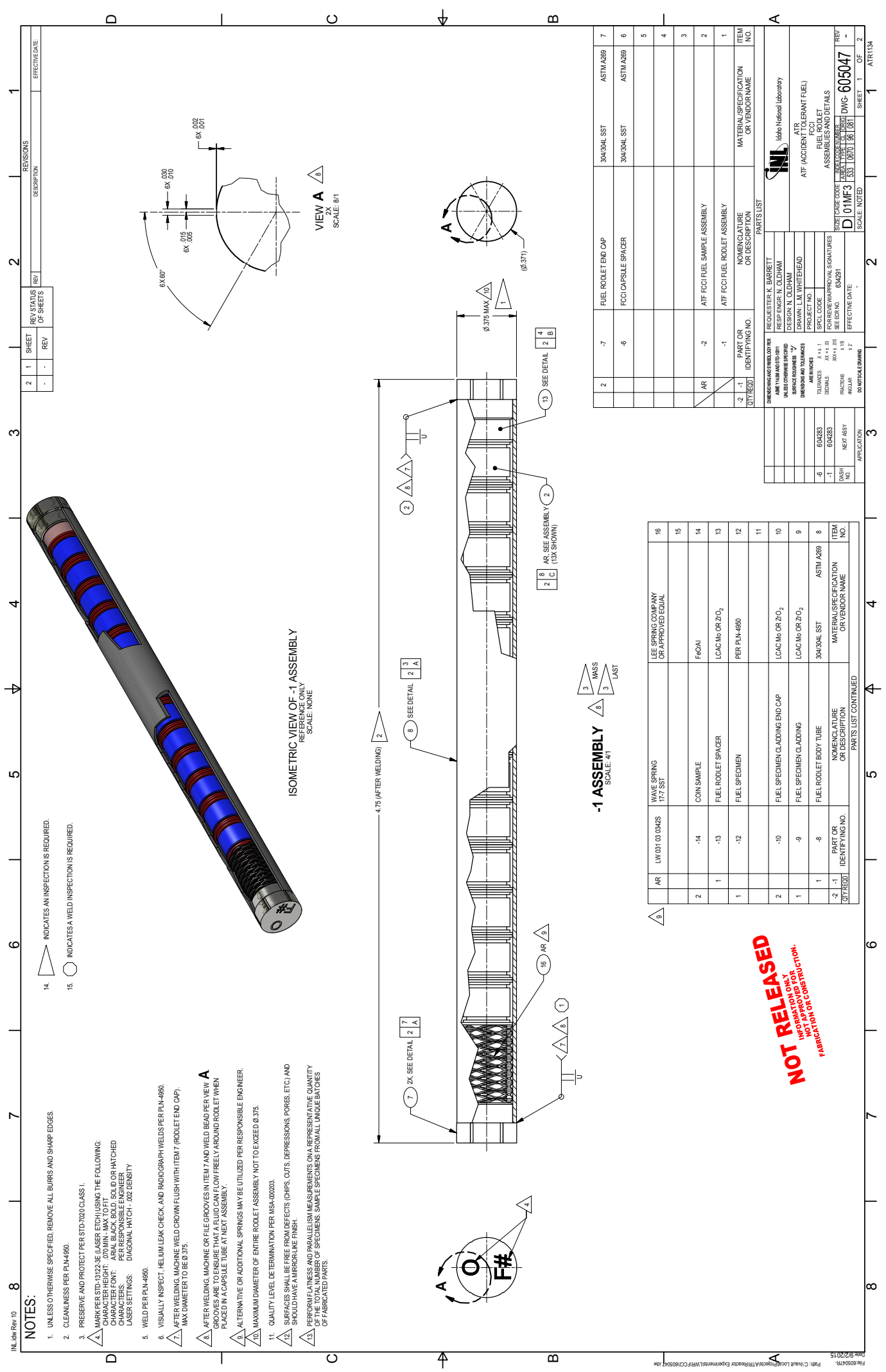

B-1 